\title{
Pyoderma gangrenosum in burn
}

\section{Image Article}

This was a 25 -year-old woman with no known defects who was a victim of a forearm burn $\mathrm{f} 8$ months ago and then she applied some herbs on it. In the face of delayed healing, the patient presented to the emergency room.

The dermatological examination had objectified an ulceration of the anterior aspect of the forearm $4 \mathrm{~cm}$ long axis, well limited with an infiltrated base and purple rim, covered with a meliceric crust (Figure1a-b). The skin biopsy was in favor of a pyoderma gangrenosum. The patient was treated by oral corticotherapy with good evolution.

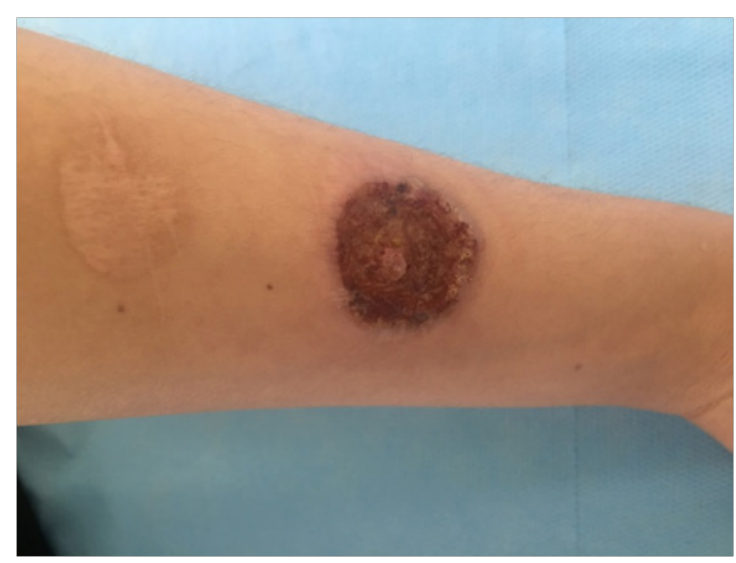

Figurela

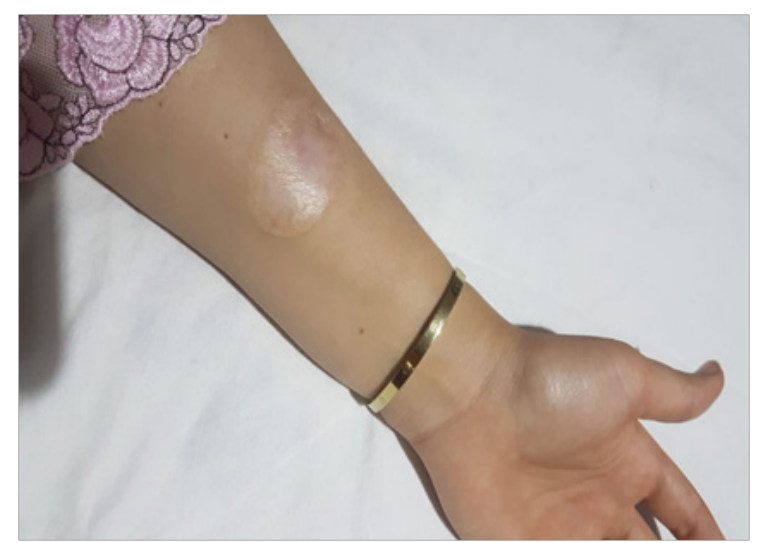

Figure I(a-b) Ulcerations well limited, with raised, erythematous - purplish and inflammatory margins and evolution after treatement.

Pyoderma gangrenosum $(\mathrm{PG})$ is a rare ulcerative neutrophilic skin condition of unknown etiology. ${ }^{1}$ However there are some hypotheses
Volume 3 Issue 4 - 2019

Aicha Elharrouni Alaoui, Zakia Douhi, Sara
Elloudi, Hanane Baybay, Fz Mernissi

Departement of dermatology, CHU Hassan II, Morocco

Correspondence: Aicha Elharrouni Alaoui, Departement of dermatology, CHU Hassan II, FES, Morocco,

Email ealaouiaicha@gmail.com

Received: August 15, 2019 | Published: August 29, 2019

about its etiology : genetic, immunologic and vascular factors. ${ }^{2} \mathrm{PG}$ can be associate with inflammatory, infectious or malignant pathologies or be idiopathic. ${ }^{2}$ It presents initially with coalescent inflammatory pustules, which fuse progressively leaving a necrotic ulcer, with hypertrophic edges well defined, and purplish color.

PG in burns wounds is rare and may occur many years following the initial injury. It can develop on any of the injured tissue. ${ }^{3}$ PG should be suspected in any burn wound that is failing to heal or rapidly deteriorates. Surgery should be avoided as this can cause further morbidity and worsening of the PG. Appropriate medical treatment generally results in rapid resolution. We report a case of Pyoderma gangrenosum in burn confirmed by histopathological examination and treated by oral corticotherapy with good evolution.

\section{Acknowledgments}

None.

\section{Conflicts of interest}

The authors report no conflicts of interest.

\section{Funding}

None.

\section{References}

1. Afi fi L, Sanchez IM, Wallace MM, et al. Diagnosis and management of peristomal pyoderma gangrenosum: A systematic review. $J$ Am Acad Dermatol. 2018;78(6):1195-1204.

2. Yalçin T, Öykü M. Pyoderma gangrenosum. J Turk Acad Dermatol. 2007;1(3):71301.

3. Rabhi F, Zaouak A, Koubaa W, et al. Pyoderma Gangrénosum: à propos de 14 cas. Rev Méd Intern. 2017;38(2): A224-A225. 